\title{
Germinação de sementes de tomateiro em diferentes temperaturas: Variabilidade fenotípica e heterose
}

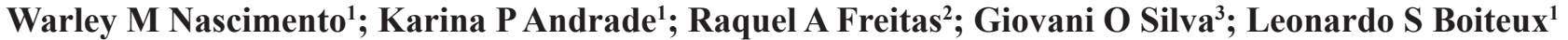

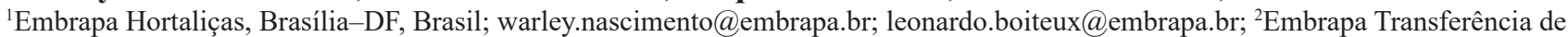 \\ Tecnologia, Uberlândia-MG, Brasil; raquel.freitas@embrapa.br; ${ }^{3}$ Embrapa Hortaliças/SPM, Canoinhas-SC, Brasil; geovani.olegario@ \\ embrapa.br
}

\section{RESUMO}

Uma alternativa para aumentar a qualidade e desempenho da germinação de sementes de tomateiro (Solanum lycopersicum), especialmente em condições ambientais adversas, é explorar, via estratégias de melhoramento, a variabilidade genética existente dentro do germoplasma dessa espécie. A velocidade e a percentagem de germinação de sementes de acessos ou cultivares de tomateiro são influenciadas por diversos fatores genéticos e ambientais. $\mathrm{O}$ fator temperatura influencia a germinação de forma expressiva. No presente trabalho, características qualitativas bem como a germinação de sementes em diferentes temperaturas foram avaliadas nas linhagens maternas, paternas e nas gerações $F_{1}$ duplo-recíprocas (linhagem materna $\mathrm{x}$ linhagem paterna e linhagem paterna $\mathrm{x}$ linhagem materna) de quatro híbridos de tomate para consumo in natura (San Vito, Duradoro, Finestra e Fontana). A qualidade das sementes das linhagens e híbridos duplo-recíprocos foi avaliada pelos seguintes testes e determinações: massa de 1000 sementes; germinação a 15, 25 e $35^{\circ} \mathrm{C}$; primeira contagem a 15,25 e $35^{\circ} \mathrm{C}$; envelhecimento acelerado e, emergência de plântulas. A alta temperatura $\left(35^{\circ} \mathrm{C}\right)$ reduziu a germinação de todos os acessos. Os resultados obtidos com os cruzamentos duplo-recíprocos, considerando o caráter resposta de germinação a diferentes temperaturas, evidenciaram um efeito significativo dos parentais sobre os híbridos. Efeito materno foi observado em 'San Vito' e 'Fontana' e efeito paterno foi observado no híbrido Finestra. Heterose foi observada para algumas das características avaliadas em 'San Vito' e 'Finestra'.

\begin{abstract}
Effects of temperature on tomato seed germination: Phenotypic variability and heterosis

Exploitation of the existing genetic variability in tomato germplasm via breeding strategies is one alternative to improve the germination under adverse environmental conditions and to provide seeds with better quality and performance. The rate and percentage of germination of tomato seeds are influenced by several genetic and environmental factors. Temperature is one of the major factors capable of influencing tomato seed germination parameters. In the present work, the female and male inbred lines of four fresh-market tomato hybrids (San Vito, Duradoro, Finestra, and Fontana) as well as the reciprocal (maternal line x paternal line and paternal line $\mathrm{x}$ maternal line) $F_{1}$ crosses were evaluated for seed quality traits and germination ability at different temperatures. The seed traits were evaluated using five tests: mass of 1000 seeds; germination at $15^{\circ} \mathrm{C}, 25^{\circ} \mathrm{C}$, and $35^{\circ} \mathrm{C}$; first count at $15^{\circ} \mathrm{C}, 25^{\circ} \mathrm{C}$ and $35^{\circ} \mathrm{C}$, accelerated aging, and seedling emergence. Higher temperatures $\left(35^{\circ} \mathrm{C}\right)$ decreased the germination in all evaluated accessions. Significant effects of the inbred lines on performance of the hybrids were observed for germination at different temperatures as indicated by the analysis of the reciprocal crosses. Maternal (female) effects were observed for some traits in the hybrids San Vito and Fontana. Male effects were observed for the hybrid Finestra. Heterotic effects were observed for some traits in the hybrids San Vito and Finestra.
\end{abstract}

Keywords: Solanum lycopersicum, physiological quality, heterosis. heterose.

(Recebido para publicação em 4 de março de 2015; aceito em 27 de novembro de 2015) (Received on March 4, 2015; accepted on November 27, 2015)

$\mathrm{O}$ tomateiro (Solanum lycopersicum) é uma das principais hortaliças em termos sociais e econômicos, sendo uma importante fonte de emprego e renda no Brasil (Filgueira, 2003; Vilela et al., 2012). O tomateiro também é uma das espécies de maior valor de vendas de sementes no Brasil e no mundo. O mercado de sementes de tomate expan- diu a nível global especialmente após a introdução dos híbridos do segmento "longa vida" (Pontes, 2006; Nascimento, 2009). Nas duas últimas décadas, a utilização de sementes híbridas no Brasil apresentou um grande incremento, tornando-se uma atividade extremamente lucrativa para as companhias produtoras de sementes (Giordano et al., 2003;
Boiteux et al., 2008, 2012a). As vantagens da utilização de sementes híbridas, mesmo em espécies autógamas como o tomateiro, são bastante conhecidas no que diz respeito à heterose, uniformidade, precocidade e "piramidização" de genes dominantes de resistência a várias doenças (Miranda et al., 1982; Maluf et al., 1983; Giordano et al., 2003). Uma 
importante preocupação na produção comercial de sementes de tomate tem sido aliar a utilização de cultivares adaptadas e capazes de produzir sementes de alta qualidade genética, física e fisiológica. Esta combinação de fatores permite que as sementes germinem rapidamente e produzam plântulas vigorosas, uniformes e sadias, assegurando um adequado estabelecimento das mudas (Bewley \& Black, 1994).

A velocidade, a percentagem e a uniformidade de germinação de sementes são características adaptativas cruciais para a viabilidade do tomateiro em condições naturais (Koornneef et al., 2002), sendo influenciadas por fatores genéticos (genótipo), por fatores intrínsecos da semente (vigor, viabilidade, longevidade, grau de maturidade e dormência) e por fatores ambientais (água, temperatura, luz e oxigênio). Estes fatores também são influenciados por práticas de manejo durante e após a colheita (Marcos Filho, 2005). O fator temperatura influencia a germinação de forma expressiva, tanto por sua ação sobre a velocidade de absorção de água bem como seu impacto sobre as reações bioquímicas e fisiológicas que controlam todo o processo. A temperatura afeta, não só o total de sementes germinadas, como também a velocidade de germinação (Bewley \& Black, 1994; Carvalho \& Nakagawa, 2000). Por exemplo, a taxa inicial de embebição e a temperatura ambiente podem alterar acentuadamente a germinação e a qualidade (vigor) da semente (Castro \& Hilhorst, 2004). Cada espécie apresenta uma temperatura mínima, máxima e ótima para a germinação. Dentro dessas faixas de temperatura podem existir diferenças marcantes entre as cultivares e acessos de uma mesma espécie vegetal (Nascimento, 2000).

Uma alternativa para incrementar o poder germinativo das sementes é a exploração da variabilidade fenotípica e genética natural existente no germoplasma de uma dada espécie vegetal, buscando uma melhor qualidade e desempenho da semente via melhoramento genético de cultivares (Maluf \& Tigchelaar, 1980, 1982; Fernandes et al., 1999). Por exemplo, diferenças significativas entre porcentagem e tempo médio de germinação foram observadas entre cultivares de Capsicum annuum (Gerson \& Honma, 1978) e tomateiro (Maluf \& Tigchelaar, 1980, 1982), tanto em baixas como em altas temperaturas, indicando tratar-se de um caráter de natureza herdável (Foolad \& Lin, 1998; Koornneef et al., 2002). Neste contexto, o objetivo do presente trabalho foi identificar a variabilidade genética para germinação de sementes em diferentes temperaturas em linhagens e híbridos comerciais de quatro segmentos varietais de tomateiro para consumo in natura: longa-vida, ornamental, saladete (italiano) e cereja.

\section{MATERIAL E MÉTODOS}

O experimento foi conduzido na área experimental e no laboratório de sementes da Embrapa Hortaliças em Brasília-DF. Foram utilizadas sementes de tomate das linhagens maternas e paternas dos seguintes híbridos $\mathrm{F}_{1}$ : San Vito (saladete), Duradoro (longa-vida devido à presença do gene rin), Finestra (ornamental) e Fontana (segmento cereja do tipo "cocktail cherry"). Após a semeadura e produção das mudas em condições de telado, estas foram transplantadas para vasos de $5 \mathrm{~L}$ contendo solo autoclavado. Para cada híbrido foram avaliadas as seguintes gerações: a) linhagem feminina (materna) autofecundada; b) linhagem masculina (paterna) autofecundada; c) híbrido \#1: direto (linhagem materna $\mathrm{x}$ linhagem paterna); d) híbrido \#2: recíproco (linhagem paterna $x$ linhagem materna), totalizando 16 tratamentos. Foram utilizados dez vasos (plantas) por tratamento. As plantas foram mantidas em condições de telado e os tratos culturais realizados de acordo com as recomendações de Filgueira (2003). O tutoramento de todas as plantas foi feito individualmente. Para a obtenção de sementes da geração $F_{1}$ de todos os híbridos, os botões florais das respectivas linhagens maternas e paternas foram emasculados antes da antese para evitar autofecundação (Boiteux et al., 2012b). Os estames foram removidos com auxílio de pinças. O pólen foi coletado de flores completamente abertas, colhidas de todas as linhagens maternas e paternas. Cruzamentos controlados foram executados imediatamente após a coleta do pólen das linhagens correspondentes a cada híbrido $\mathrm{F}_{1}$. As flores emasculadas foram polinizadas manualmente $\mathrm{e}$ identificadas com etiquetas referentes a cada tratamento (Boiteux et al., 2012b).

Foram realizadas sete colheitas dos frutos, em intervalos semanais, sendo a primeira colheita realizada aos 89 dias após a semeadura para o híbrido 'Finestra' e 96 dias para os híbridos 'San Vito', 'Duradoro' e 'Fontana'. Após a colheita, os frutos foram pesados, em balança analítica e os resultados expressos em gramas. Em seguida, as sementes foram extraídas manualmente. As sementes e o líquido placentário foram depositados em recipientes plásticos e fermentados por um período de 24 até $48 \mathrm{~h}$ (dependo da temperatura). Posteriormente, as sementes foram lavadas em água corrente e secas (à temperatura ambiente) por uma hora e então transferidas para uma sala de pré-secagem (temperatura de $32^{\circ} \mathrm{C}$ ) por 24 horas. As sementes secas foram beneficiadas em soprador pneumático. Após o término de todas as colheitas, as sementes foram misturadas de acordo com os respectivos tratamentos e secas em estufa a $38^{\circ} \mathrm{C}$ por 24 horas. Em seguida foram submetidas aos seguintes testes e determinações:

Rendimento de sementes - Após a secagem, as sementes foram pesadas em balança analítica com três casas decimais, para determinação da produção de sementes através da relação: gramas de sementes $/ \mathrm{kg}$ de fruto.

Massa de 1000 sementes - Essa avaliação foi efetuada com oito repetições de 100 sementes, em balança analítica com precisão de três casas decimais, sendo os resultados expressos em gramas.

Germinação - Para essa determinação foram utilizadas quatro repetições de 50 sementes acondicionadas em caixas "gerbox" sobre duas folhas de papel mata-borrão umedecidas com água destilada, na proporção de 2,5 vezes a massa do papel seco. As sementes foram mantidas em estufas tipo BOD nas seguintes temperaturas constantes: 15,25 e $35^{\circ} \mathrm{C}$. As avaliações da porcentagem de protrusão da raiz primária 
foram realizadas aos cinco e aos 14 dias após a instalação do teste (Brasil, 2009).

Primeira contagem - Essa determinação consistiu do registro da porcentagem de sementes germinadas obtidas no quinto dia após a instalação do teste de germinação.

Envelhecimento acelerado - Foi utilizada uma metodologia de análise essencialmente como descrita em Jianhua \& McDonald (1996). Amostras de cada tratamento foram uniformemente distribuídas sobre tela de alumínio, fixada em caixas plásticas tipo "gerbox", contendo ao fundo, $40 \mathrm{~mL}$ de solução saturada de $\mathrm{NaCl}$ (40 g de $\mathrm{NaCl}$ em $100 \mathrm{~mL}$ de água). As caixas contendo as sementes foram fechadas e mantidas a $41^{\circ} \mathrm{C}$, por 72 horas. Decorrido este período, as sementes foram submetidas ao teste de germinação, conforme metodologia descrita anteriormente. As sementes foram colocadas para germinar em estufa tipo BOD, à temperatura alternada de $20-30^{\circ} \mathrm{C}$ e fotoperíodo de 8 horas de luz e 16 horas de escuro. A porcentagem de protrusão da raiz primária foi avaliada aos cinco dias após a instalação do teste.

\section{Emergência de plântulas em casa}

de vegetação - Foram utilizadas quatro repetições de 50 sementes de cada tratamento. Uma semente por célula foi colocada em bandeja de poliestireno expandido ("isopor") de 200 células, contendo substrato comercial Plant$\max ^{\circledR}$. A irrigação foi feita sempre que necessário. A porcentagem de plântulas emergidas foi obtida aos 14 dias após a semeadura.

Delineamento experimental - Foi adotado um delineamento inteiramente casualizado, com quatro repetições. Os dados foram submetidos à análise de variância e a comparação de médias foi procedida pelo teste de Scott-Knott a $5 \%$ de probabilidade utilizando-se o programa computacional Genes (Cruz, 2001). Os dados de primeira contagem nas temperaturas de 15,25 e $35^{\circ} \mathrm{C}$ e envelhecimento acelerado foram transformados em arco seno da raiz quadrada da proporção. Entretanto, mesmo após a transformação, os dados de primeira contagem a $35^{\circ} \mathrm{C}$ não atenderam à pressuposição de normalidade de distribuição.

\section{RESULTADOS E DISCUSSÃO}

Dentre os 16 tratamentos avaliados,

Tabela 1. Rendimento de sementes das linhagens materna, paterna, híbrido \#1 (direto) e híbrido \#2 (recíproco) das cultivares híbridas de tomate San Vito, Duradoro, Finestra e Fontana (seed yield of the male and female inbred lines as well as the reciprocal hybrids of tomato cultivars San Vito, Duradoro, Finestra, and Fontana). Brasília, Embrapa Hortaliças, 2011.

\begin{tabular}{lc}
\hline Material genético/acesso & Sementes $(\mathbf{g} / \mathbf{k g}$ de fruto) \\
\hline Linhagem materna San Vito & 1,05 \\
Linhagem paterna San Vito & 1,11 \\
Híbrido \#1 (mãe x pai) San Vito & 1,40 \\
Híbrido \#2 (pai x mãe) San Vito & 1,31 \\
Linhagem materna Duradoro & 1,79 \\
Linhagem paterna Duradoro & 0,73 \\
Híbrido \#1 (mãe x pai) Duradoro & 2,33 \\
Híbrido \#2 (pai x mãe) Duradoro & 0,73 \\
Linhagem materna Finestra & 1,20 \\
Linhagem paterna Finestra & 2,44 \\
Híbrido \#1 (mãe x pai) Finestra & 0,77 \\
Híbrido \#2 (pai x mãe) Finestra & 5,43 \\
Linhagem materna Fontana & 5,81 \\
Linhagem paterna Fontana & 1,01 \\
Híbrido \#1 (mãe x pai) Fontana & 3,82 \\
Híbrido \#2 (pai x mãe) Fontana & 1,06 \\
\hline
\end{tabular}

a linhagem materna do híbrido 'Fontana' e o híbrido recíproco (linhagem paterna $\mathrm{x}$ linhagem materna) de 'Finestra' foram os que obtiveram os maiores rendimentos de sementes com 5,81 e $5,43 \mathrm{~g} / \mathrm{kg}$ de fruto, respectivamente (Tabela 1). Os menores rendimentos de sementes foram apresentados pela linhagem paterna do híbrido Duradoro e pelo híbrido recíproco (linhagem paterna $\mathrm{x}$ linhagem materna) de Duradoro, ambos com 0,73 $\mathrm{g}$ de semente/kg de fruto (Tabela 1). Dessa forma, analisando o fator produção de sementes, a opção do híbrido direto (linhagem materna x linhagem paterna) para 'Duradoro', mostra-se mais vantajosa em relação ao híbrido recíproco \#2.

Não foram observadas diferenças significativas nas primeiras contagens a 15 e $25^{\circ} \mathrm{C}$ em relação aos genitores da cultivar San Vito e os seus híbridos correspondentes. Portanto, a direção do cruzamento não apresentou uma marcante influência sobre vigor das sementes nessa combinação híbrida (Tabela 2). A maior porcentagem de germinação observada no teste de primeira contagem foi obtida a $25^{\circ} \mathrm{C}$. Em regime de temperatura de $35^{\circ} \mathrm{C}$ a germinação obtida no teste de primeira contagem foi totalmente inibida, tanto para as linhagens quanto para os híbridos (Tabela 2), indicando não haver variabilidade genética para esta característica neste grupo de acessos. Por sua vez, o teste de germinação a $15^{\circ} \mathrm{C}$ detectou diferenças significativas entre os materiais genéticos relacionados com o híbrido San Vito, com superioridades para a linhagem materna e o híbrido direto (híbrido \#1), sugerindo um efeito de origem maternal (Tabela 2). Estes dados estão de acordo com ensaios preliminares conduzidos por Nascimento et al. (2007), que haviam observado a superioridade da linhagem materna da cultivar San Vito em relação à paterna bem como em relação aos híbridos duplo-recíprocos. Os resultados do teste de germinação a $35^{\circ} \mathrm{C}$ mostraram um desempenho superior do híbrido direto (híbrido \#1) em relação aos genitores da cultivar San Vito (Tabela 2), evidenciando assim, o efeito positivo da heterose em condições de estresse por temperatura mais elevada. Esses resultados são discordantes dos obtidos previamente por Nascimento et 
Tabela 2. Primeira contagem (PC) (\%) e germinação (G) (\%) em diferentes temperaturas das sementes das linhagens materna, paterna, híbrido \#1 (direto) e híbrido \#2 (recíproco) da cultivar híbrida de tomate saladete San Vito \{first count (PC) (\%) and germination (G) (\%) at distinct temperatures of the male and female inbred lines as well as the reciprocal hybrids of the saladete-type cultivar San Vito\}. Brasília, Embrapa Hortaliças, 2011.

\begin{tabular}{|c|c|c|c|c|c|c|}
\hline \multirow{2}{*}{ Material genético/acesso } & \multicolumn{2}{|c|}{$15^{\circ} \mathrm{C}$} & \multicolumn{2}{|c|}{$25^{\circ} \mathrm{C}$} & \multicolumn{2}{|c|}{$35^{\circ} \mathrm{C}$} \\
\hline & $\mathbf{P C}$ & G & PC & $\mathbf{G}$ & PC & $\mathbf{G}$ \\
\hline Linhagem materna & $1 * \mathrm{a}$ & $95 \mathrm{a}$ & $37 \mathrm{a}$ & $89 \mathrm{~b}$ & 0 & $6 \mathrm{~b}$ \\
\hline Linhagem paterna & $0 \mathrm{a}$ & $70 \mathrm{~b}$ & $17 \mathrm{a}$ & $62 \mathrm{~d}$ & 0 & $0 \mathrm{c}$ \\
\hline Híbrido \#1 (mãe x pai) & $4 \mathrm{a}$ & 97 a & $26 \mathrm{a}$ & 96 a & 0 & $13 \mathrm{a}$ \\
\hline Híbrido \#2 (pai x mãe) & $0 \mathrm{a}$ & $76 \mathrm{~b}$ & $27 \mathrm{a}$ & $81 \mathrm{c}$ & 0 & $6 \mathrm{~b}$ \\
\hline CV (\%) & 137,08 & 5,64 & 16,47 & 4,76 & - & 51,43 \\
\hline
\end{tabular}

*Médias seguidas de mesma letra na coluna não diferem entre si pelo teste Scott-Knott a $5 \%$ de probabilidade (values followed by the same letter in the column are not statistically different using the Scott-Knott test 5\% probability).

Tabela 3. Primeira contagem (PC) $(\%)$ e germinação $(\mathrm{G})(\%)$ em diferentes temperaturas das sementes das linhagens materna, paterna, híbrido \#1 (direto) e híbrido \#2 (recíproco) da cultivar híbrida de tomate longa-vida Duradoro ffirst count (PC) (\%) and germination (G) $(\%)$ at distinct temperatures of the male and female inbred lines as well as the reciprocal hybrids of the long shelf-life tomato cultivar Duradoro \}. Brasília, Embrapa Hortaliças, 2011.

\begin{tabular}{|c|c|c|c|c|c|c|}
\hline \multirow{2}{*}{ Material genético/acesso } & \multicolumn{2}{|c|}{$15^{\circ} \mathrm{C}$} & \multicolumn{2}{|c|}{$25^{\circ} \mathrm{C}$} & \multicolumn{2}{|c|}{$35^{\circ} \mathrm{C}$} \\
\hline & PC & G & PC & G & PC & G \\
\hline Linhagem materna & $0 * \mathrm{a}$ & $68 \mathrm{a}$ & $4 \mathrm{a}$ & $59 \mathrm{~b}$ & 1 & $1 \mathrm{a}$ \\
\hline Linhagem paterna & $0 \mathrm{a}$ & $77 \mathrm{a}$ & $5 \mathrm{a}$ & $83 \mathrm{a}$ & 0 & $0 \mathrm{a}$ \\
\hline Híbrido \#1 (mãe x pai) & $0 \mathrm{a}$ & $83 \mathrm{a}$ & $10 \mathrm{a}$ & $80 \mathrm{a}$ & 0 & $0 \mathrm{a}$ \\
\hline Híbrido \#2 (pai x mãe) & $0 \mathrm{a}$ & $76 \mathrm{a}$ & $2 \mathrm{~b}$ & $68 \mathrm{~b}$ & 0 & $2 \mathrm{a}$ \\
\hline CV (\%) & 32,63 & 10,02 & 40,64 & 10,69 & - & 158,22 \\
\hline
\end{tabular}

*Médias seguidas de mesma letra na coluna não diferem entre si pelo teste Scott-Knott a $5 \%$ de probabilidade (values followed by the same letter in the column are not statistically different using the Scott-Knott test 5\% probability).

al. (2007) que não constataram efeito da heterose na cultivar San Vito para germinação em alta temperatura $\left(35^{\circ} \mathrm{C}\right)$.

As linhagens e os duplo-recíprocos associados com a cultivar Duradoro não diferiam significativamente nos testes de primeira contagem e germinação a $15^{\circ} \mathrm{C}$ (Tabela 3). Novos ensaios devem ser conduzidos uma vez que uma variação significativa entre os diferentes genótipos de tomateiro pode se manifestar mais claramente em experimentos conduzidos a $10^{\circ} \mathrm{C}$ (Potaczek \& Kozik, 2000). A germinação e o vigor no teste de primeira contagem foram inibidos a $35^{\circ} \mathrm{C}$ (Tabela 3 ). A taxa inicial de embebição e a temperatura podem alterar acentuadamente a germinação e a qualidade (vigor) das sementes. No teste de primeira contagem a $25^{\circ} \mathrm{C}$ houve diferença significativa entre os genótipos (Tabela 3), sendo que o híbrido recíproco (híbrido \#2) mostrou-se como o de menor vigor. Esta diferença entre os híbridos pode ser justificada pela direção do cruzamento, uma vez que o híbrido \#1 obteve $10 \%$ de germinação, superior às linhagens materna (4\%) e paterna ( $5 \%$ ); já o híbrido \#2 obteve a menor germinação $(2 \%)$ com desempenho inferior aos genitores. A germie entre os híbridos (Tabela 3). Campos \& Tillmann (1997), avaliando as cultivares Floradade e Gaúcho, observaram diferenças significativas na primeira contagem a $25^{\circ} \mathrm{C}$ entre as cultivares; no entanto, não verificaram diferenças na germinação a $25^{\circ} \mathrm{C}$.

Com relação ao híbrido ornamental Finestra, os resultados do teste de primeira contagem a 15 e $25^{\circ} \mathrm{C}$ mostraram diferenças significativas entre os genótipos, sendo a linhagem paterna nação a $25^{\circ} \mathrm{C}$ diferiu entre os genitores superior aos outros tratamentos (Tabela 4). Foolad et al. (1999) observaram que um acesso tolerante à salinidade (S. lycopersicum 'PI-120256') quando usado como linhagem paterna germinou mais rápido do que o acesso 'UCT5' (linhagem materna) sob condições de baixa temperatura, melhorando a taxa de germinação da progênie. Já no teste de germinação, tanto a $15^{\circ} \mathrm{C}$ quanto a $25^{\circ} \mathrm{C}$, os híbridos obtiveram desempenhos superiores aos genitores, não havendo diferenças quanto à direção do cruzamento. Na germinação a $35^{\circ} \mathrm{C}$ observou-se diferenças significativas entre os genótipos, evidenciando herança de efeito paterno no híbrido Finestra (Tabela 4).

Os resultados do teste de primeira contagem a $15^{\circ} \mathrm{C}$ diferiram significativamente entre os genótipos evidenciando um efeito materno do híbrido Fontana (Tabela 5). O efeito materno é um caso especial de herança controlada por genes da mãe, onde os resultados do cruzamento direto e do cruzamento recíproco se mostram diferentes (Ramalho et al., 2001). Essa é a principal explicação para os resultados de cruzamentos recíprocos, sabendo que esta diferença do cruzamento direto e do cruzamento recíproco é devida à herança materna. A expressão dessas diferenças em sementes é, de certo modo, esperada uma vez que é influenciada pelo genótipo de três tecidos com composição genética variável: a) a parte feminina da planta (que porta o fruto e que contem as sementes em desenvolvimento) contribui com a testa; $b$ ) o endosperma triplóide que nutre o embrião em desenvolvimento e c) o embrião diplóide. O efeito maternal pode ser resultado da contribuição mais substancial para o desenvolvimento do genótipo maternal para a testa e/ou endosperma, enquanto o efeito zigótico poderia ser resultado da contribuição equitativa dos genótipos maternal e paternal (Orsi \& Tanksley, 2009). O conhecimento deste tipo de herança é imprescindível para a eficiência de programas de seleção. Por exemplo, em pimentão ( $C$. annuum cv. Ikeda) as sementes selecionadas pelo teste de frio foram as que melhor transmitiram essas características para as progênies (Fernandes et al., 1999).

$\mathrm{O}$ teste de primeira contagem a $25^{\circ} \mathrm{C}$ 
Tabela 4. Primeira contagem (PC) (\%) e germinação (G) (\%) em diferentes temperaturas das sementes das linhagens materna, paterna, híbrido \#1 (direto) e híbrido \#2 (recíproco) da cultivar híbrida de tomate ornamental Finestra ffirst count (PC) (\%) and germination (G) (\%) at distinct temperatures of the male and female inbred lines as well as the reciprocal hybrids of the ornamental tomato cultivar Finestra\}. Brasília, Embrapa Hortaliças, 2011.

\begin{tabular}{|c|c|c|c|c|c|c|}
\hline \multirow{2}{*}{ Material genético/acesso } & \multicolumn{2}{|c|}{$15^{\circ} \mathrm{C}$} & \multicolumn{2}{|c|}{$25^{\circ} \mathrm{C}$} & \multicolumn{2}{|c|}{$35^{\circ} \mathrm{C}$} \\
\hline & PC & G & PC & G & PC & G \\
\hline Linhagem materna & $1 * b$ & $87 \mathrm{~b}$ & $8 \mathrm{~b}$ & $89 \mathrm{~b}$ & 1 & $9 \mathrm{~b}$ \\
\hline Linhagem paterna & $25 \mathrm{a}$ & $78 \mathrm{c}$ & $29 \mathrm{a}$ & $75 \mathrm{c}$ & 27 & $39 \mathrm{a}$ \\
\hline Híbrido \#1 (mãe x pai) & $0 \mathrm{~b}$ & $100 \mathrm{a}$ & $0 \mathrm{c}$ & $98 \mathrm{a}$ & 0 & $9 \mathrm{~b}$ \\
\hline Híbrido \#2 (pai x mãe) & $0 \mathrm{~b}$ & $98 \mathrm{a}$ & $6 \mathrm{~b}$ & $97 \mathrm{a}$ & 1 & $31 \mathrm{a}$ \\
\hline $\mathrm{CV}(\%)$ & 47,17 & 4,79 & 41,10 & 4,25 & - & 28,47 \\
\hline
\end{tabular}

*Médias seguidas de mesma letra na coluna não diferem entre si pelo teste Scott-Knott a $5 \%$ de probabilidade (values followed by the same letter in the column are not statistically different using the Scott-Knott test 5\% probability).

Tabela 5. Primeira contagem (PC) (\%) e germinação (G) (\%) em diferentes temperaturas das sementes das linhagens materna, paterna, híbrido \#1 (direto) e híbrido \#2 (recíproco) da cultivar híbrida de tomate "cocktail cherry" Fontana ffirst count (PC) (\%) and germination (G) (\%) at distinct temperatures of the male and female inbred lines as well as the reciprocal hybrids of the cocktail cherry tomato cultivar Fontana\}. Brasília, Embrapa Hortaliças, 2011.

\begin{tabular}{|c|c|c|c|c|c|c|}
\hline \multirow[b]{2}{*}{ Material genético/acesso } & \multicolumn{2}{|c|}{$15^{\circ} \mathrm{C}$} & \multicolumn{2}{|c|}{$25^{\circ} \mathrm{C}$} & \multicolumn{2}{|c|}{$35^{\circ} \mathrm{C}$} \\
\hline & PC & G & PC & G & PC & G \\
\hline Linhagem materna & $50 * \mathrm{a}$ & $94 \mathrm{a}$ & $24 \mathrm{a}$ & $90 \mathrm{a}$ & 0 & $0 \mathrm{~b}$ \\
\hline Linhagem paterna & $3 b$ & $95 \mathrm{a}$ & $0 \mathrm{c}$ & $87 \mathrm{a}$ & 0 & $3 \mathrm{a}$ \\
\hline Híbrido \#1 (mãe x pai) & $40 \mathrm{a}$ & $95 \mathrm{a}$ & $8 \mathrm{~b}$ & $86 \mathrm{a}$ & 0 & $0 \mathrm{~b}$ \\
\hline Híbrido \#2 (pai x mãe) & $5 \mathrm{~b}$ & $90 \mathrm{a}$ & $0 \mathrm{c}$ & $83 \mathrm{a}$ & 0 & $5 \mathrm{a}$ \\
\hline CV $(\%)$ & 60,67 & 5,45 & 57,24 & 6,73 & - & 104,23 \\
\hline
\end{tabular}

*Médias seguidas de mesma letra na coluna não diferem entre si pelo teste Scott-Knott a $5 \%$ de probabilidade (values followed by the same letter in the column are not statistically different using the Scott-Knott test 5\% probability).

mostrou haver diferença significativa entre os genitores do híbrido Fontana, sendo a linhagem materna a mais vigorosa (Tabela 5). À semelhança do que ocorreu com a cultivar Finestra, na germinação a $35^{\circ} \mathrm{C}$ observou-se diferença significativa entre os genótipos evidenciando herança de efeito paterno, embora tenha apresentado baixo percentual de germinação (Tabela 5).

$\mathrm{O}$ vigor das sementes avaliado pelo teste de envelhecimento acelerado indicou as sementes das linhagens maternas e dos híbridos diretos, para as cultivares San Vito e Fontana como as mais vigorosas (Tabela 6). Para o híbrido San Vito, esses resultados estão de acordo com a germinação em condições de baixa temperatura (Tabela 2).

$\mathrm{O}$ teste de emergência de plântulas pode avaliar o vigor de um lote pela precocidade de emissão da raiz primária (Martins et al., 2006). Os resultados do teste de emergência de plântulas diferiram entre os genótipos (Tabela 6). Os tratamentos que apresentaram melhor vigor foram os genitores e os híbridos \#1 e \#2 de 'San Vito', a linhagem paterna e o híbrido \#2 de Duradoro, a linhagem materna e os híbridos \#1 e \#2 de 'Finestra' e a linhagem paterna de 'Fontana'.

O tamanho das sementes é um fator de importância na velocidade de emergência das plântulas e, geralmente, sementes grandes são mais vigorosas quando comparadas com sementes pequenas (Menezes et al., 1991). A combinação de sementes grandes e vigor de plântulas são consideradas, em condições naturais, como características coadaptadas (Silvertown, 1981). As sementes de espécies domesticadas de to- mateiro apresentam uma tendência para serem maiores que aquelas das espécies selvagens (Doganlar et al., 2000). A característica de maior massa de semente é muito provavelmente associada com uma resposta da pressão de seleção pós-domesticação para características tais como rendimento, germinação uniforme e vigor da plântula (Doganlar et al., 2000). No presente experimento foram verificadas diferenças significativas na massa de 1000 sementes. No entanto, as sementes de maior massa não foram necessariamente as mais vigorosas (Tabela 6). Sementes de maior tamanho apresentam, geralmente, maiores teores de reservas nutricionais que podem ser mobilizadas durante o desenvolvimento e apresentando embriões bem formados, sendo potencialmente as mais vigorosas (Carvalho \& Nakagawa, 2000) e com maior longevidade (Silvertown, 1981). Provavelmente, as sementes de maior massa apresentam (por unidade seca) menor reserva na composição. Essa característica pode explicar a observação de que genótipos com sementes de maior massa não corresponderam, necessariamente, aos maiores vigores (Bittencourt, 1991).

Diferenças entre híbridos duplo-recíprocos foram observadas para algumas características, incluindo produção total de sementes (Tabela 1), primeira contagem e germinação a diferentes temperaturas (Tabelas 2 a 5) bem como envelhecimento acelerado, emergência de plântulas e massa de 1000 sementes (Tabela 6). Em resumo, a temperatura mais elevada $\left(35^{\circ} \mathrm{C}\right)$ provocou uma redução significativa na germinação de todos os acessos, indicando não haver variabilidade genética para tolerância a essas condições ambientais nos acessos de tomateiro avaliados. Os resultados obtidos nos cruzamentos diretos e nos cruzamentos recíprocos (considerando o caráter temperatura) evidenciaram efeito dos parentais sobre os híbridos, ocorrendo efeito materno significativo nas cultivares San Vito e Fontana, e efeito paterno na cultivar Finestra.

Heterose (vigor de híbrido) é o aumento do vigor da progênie ou do híbrido $\mathrm{F}_{1}$ em comparação com os genitores contrastantes envolvidos em um dado cruzamento (Borém, 2001). 
Tabela 6. Dados médios obtidos para envelhecimento acelerado, emergência de plântulas e massa de 1000 sementes das linhagens maternas, paternas, dos híbridos \#1 (diretos) e híbridos \#2 (recíprocos) das cultivares híbridas de tomate San Vito, Duradoro, Finestra e Fontana (average values for accelerated aging, seedling emergence, and seed mass of the male and female inbred lines as well as the reciprocal hybrids of the tomato cultivars San Vito, Duradoro, Finestra, and Fontana). Brasília, Embrapa Hortaliças, 2011.

\begin{tabular}{lccc}
\hline Material genético/acesso & $\begin{array}{c}\text { Envelhecimento ace- } \\
\text { lerado (\%) }\end{array}$ & $\begin{array}{c}\text { Emergência de } \\
\text { plântulas (\%) }\end{array}$ & $\begin{array}{c}\text { Massa de 1000 } \\
\text { sementes (g) }\end{array}$ \\
\hline Linhagem materna San Vito & $73 * \mathrm{a}$ & $82 \mathrm{a}$ & $2,83 \mathrm{c}$ \\
Linhagem paterna San Vito & $23 \mathrm{~b}$ & $66 \mathrm{a}$ & $3,10 \mathrm{c}$ \\
Híbrido \#1 (mãe x pai) San Vito & $69 \mathrm{a}$ & $82 \mathrm{a}$ & $3,37 \mathrm{c}$ \\
Híbrido \#2 (pai x mãe) San Vito & $20 \mathrm{~b}$ & $72 \mathrm{a}$ & $3,05 \mathrm{~b}$ \\
Linhagem materna Duradoro & $2 \mathrm{c}$ & $34 \mathrm{~b}$ & $4,57 \mathrm{a}$ \\
Linhagem paterna Duradoro & $7 \mathrm{c}$ & $69 \mathrm{a}$ & $3,26 \mathrm{c}$ \\
Híbrido \#1 (mãe x pai) Duradoro & $16 \mathrm{~b}$ & $57 \mathrm{~b}$ & $4,48 \mathrm{a}$ \\
Híbrido \#2 (pai x mãe) Duradoro & $11 \mathrm{c}$ & $73 \mathrm{a}$ & $4,01 \mathrm{~b}$ \\
Linhagem materna Finestra & $5 \mathrm{c}$ & $81 \mathrm{a}$ & $3,71 \mathrm{~b}$ \\
Linhagem paterna Finestra & $24 \mathrm{~b}$ & $41 \mathrm{~b}$ & $2,28 \mathrm{~d}$ \\
Híbrido \#1 (mãe x pai) Finestra & $25 \mathrm{~b}$ & $86 \mathrm{a}$ & $3,80 \mathrm{~b}$ \\
Híbrido \#2 (pai x mãe) Finestra & $26 \mathrm{~b}$ & $75 \mathrm{a}$ & $2,54 \mathrm{~d}$ \\
Linhagem materna Fontana & $57 \mathrm{a}$ & $46 \mathrm{~b}$ & $1,78 \mathrm{e}$ \\
Linhagem paterna Fontana & $5 \mathrm{c}$ & $90 \mathrm{a}$ & $3,60 \mathrm{~b}$ \\
Híbrido \#1 (mãe x pai) Fontana & $69 \mathrm{a}$ & $61 \mathrm{~b}$ & $2,33 \mathrm{~d}$ \\
Híbrido \#2 (pai x mãe) Fontana & $18 \mathrm{~b}$ & $56 \mathrm{~b}$ & $4,32 \mathrm{a}$ \\
\hline CV (\%) & 26,57 & 21,49 & 10,71 \\
\hline
\end{tabular}

*Médias seguidas de mesma letra na coluna não diferem entre si pelo teste Scott-Knott a 5\% de probabilidade (values followed by the same letter in the column are not statistically different using the Scott-Knott test 5\% probability).

A literatura registra que o tomateiro apresenta uma grande expressão de heterose para algumas características tais como: produção total, índice de colheita (produção de frutos/biomassa total), número de frutos, precocidade e número de sementes por planta (Semel et al., 2006). Essas observações estão de acordo com os dados obtidos no presente trabalho, uma vez que o vigor de híbrido também foi verificado para produção de sementes por fruto nas cultivares San Vito e Finestra. Neste contexto, a heterose observada para alguns dos outros parâmetros de qualidade de sementes merece estudos adicionais mais detalhados visando consolidar as informações geradas no presente trabalho.

Em geral, os programas de melhoramento genético não têm tido uma marcante preocupação com o rendimento e/ ou a qualidade de sementes do material que está sendo desenvolvido. O presente trabalho indica que diferenças significativas podem ocorrer entre linhagens e entre as direções de cruzamento. Desta forma, há necessidade de novas pesquisas visando fornecer subsídios e informações mais refinadas aos programas de melhoramento genético bem como aos programas de produção de sementes dos diferentes híbridos liberados para comercialização.

\section{REFERÊNCIAS}

BEWLEY, JD; BLACK, M. 1994. Seeds physiology of development and germination. New York: Plenum Press. 445pp.

BITTENCOURT, MLC. 1991. Qualidade das sementes e avaliação das progênies de meio-irmãos de cenoura (Daucus carota L.) 'Brasília'. Viçosa: UFV. 77p (Dissertação mestrado).

BOITEUX, LS; FONSECA, MEN; GIORDANO, LB; MELO, PCT. 2012a. Melhoramento genético. In: CLEMENTE, FMVT; BOITEUX, LS (org.). Produção de tomate para processamento industrial. $1^{\mathrm{a}}$ ed., Brasília: Embrapa. p.31-50.

BOITEUX, LS; FONSECA, MEN; GIORDANO, LB; NASCIMENTO, WM. 2012b. Desenvolvimento de cultivares e híbridos de hortaliças. In: NASCIMENTO,
WM (org). Hortaliças: Tecnologia de produção de sementes. $1^{\mathrm{a}}$ ed. Brasília: Embrapa. p.37-57. BOITEUX, LS; MELO, PCT; VILELA, NJ. 2008. Tomate para consumo in natura. In: ALBUQUERQUE, ACS; SILVA, AG (eds). Desenvolvimento da agricultura tropical: Quatro décadas de inovações tecnológicas, institucionais e politicas. Brasília: Embrapa. p.557-567.

BORÉM, A. 2001. Melhoramento de plantas. $3^{\text {a }}$ ed. Viçosa: UFV. 500p.

BRASIL. 2009. Ministério da Agricultura e da Reforma Agrária. 2009. Regras para análise de sementes. Brasília: SNDA. 395p.

CAMPOS, VC; TILLMANN, MAA. 1997. Avaliação da metodologia do teste de germinação para sementes de tomate. Revista Brasileira de Agrociência 3: 37-42.

CARVALHO, NM; NAKAGAWA, J. 2000. Sementes: Ciência tecnologia e produção. $4^{\mathrm{a}}$ ed. Jaboticabal: FUNEP. 588p.

CASTRO, RD; HILHORST, HWM. 2004. Embebição e reativação do metabolismo. In: FERREIRA, AG; BORGHETTI, F. Germinação: do básico ao aplicado. Porto Alegre: Artmed. p.148-162.

CRUZ, CD. 2001. Programa genes: Aplicativo computacional em genética e estatística. Viçosa: UFV. 648p.

DOGANLAR, S; FRARY, A; TANKSLEY, SD. 2000. The genetic basis of seed-weight 
variation: Tomato as a model system. Theoretical and Applied Genetics 100: 12671273.

FERNANDES, HS; NEDEL, JL; GALLI, J. 1999. Uso de testes de vigor de sementes na detecção de variabilidade genética intracultivar em pimentão (Capsicum annuum). Pesquisa Agropecuária Brasileira 34: 1699-1703.

FILGUEIRA, FAR. 2003. Novo manual de olericultura: Agrotecnologia moderna na produção e comercialização de hortaliças. $2^{a}$ ed. Revista e ampliada. Viçosa: UFV. 412p.

FOOLAD, MR; HYMAN, JR; LIN, GY. 1999. Relationships between cold-and-salt tolerance during seed germination in tomato: Analysis of responses and correlated response to selection. Plant Breeding 118: 49-52.

FOOLAD, MR; LIN, GY. 1998. Genetic analysis of low-temperature tolerance during germination in tomato, Lycopersicon esculentum. Plant Breeding 117: 171-176.

GERSON R; HONMA S. 1978. Emergence response of the pepper at low soil temperature. Euphytica 27: 151-156.

GIORDANO, LB; ARAGÃO, FAS; BOITEUX, LS. 2003. Melhoramento genético do tomateiro. Informe Agropecuário 24: 43-57.

JIANHUA, Z; McDONALD, MB. 1996. The satured salt accelerated aging test for smallseeded crops. Seed Science and Technology 25: 123-131.

KOORNNEEF, M; BENTSINK, L; HILHORST, H. 2002. Seed dormancy and germination. Current Opinion in Plant Biology 5: 33-36.

MALUF, WR; FERREIRA, PE; MIRANDA, JEC. 1983. Genetic divergence in tomatoes and its relationship with heterosis for yield in $\mathrm{F}_{1}$ hybrids. Revista Brasileira Genética 6: $453-460$.
MALUF, WR; TIGCHELAAR, EC. 1980. Responses associated with low temperature seed germinating ability in tomato. Journal of the American Society for Horticultural Science 105: 280-283.

MALUF, WR; TIGCHELAAR, EC. 1982. Relationship between fatty acid composition and low-temperature seed germination in tomato. Journal of the American Society for Horticultural Science 107: 621-623.

MARCOS FILHO, J. 2005. Fisiologia de sementes de plantas cultivadas. Piracicaba: FEALQ. 495p.

MARTINS, CC; CASTRO, MM; SENEME, AM; NAKAGAWA, J. 2006. Metodologia para avaliação de vigor de sementes de tomate. Horticultura Brasileira 24: 301-304.

MENEZES, D; GOMES, ACS; GUIMARÃES, RM. 1991. Influência do tamanho da semente de milho (Zea mays) na sua qualidade fisiológica. Informativo ABRATES 1: 36.

MIRANDA, JEC; MALUF, WR; CAMPOS, JP. 1982. Correlações ambientais, genotípicas e fenotípicas em cruzamento dialélico de cultivares de tomate. Pesquisa Agropecuária Brasileira 17: 899-904.

NASCIMENTO, WM. 2000. Temperatura $\mathrm{x}$ germinação. Seed News 4: 44-45.

NASCIMENTO, WM. 2009. O mercado mundial e brasileiro de sementes de hortaliças e suas tendências. In: Palestras do $9^{\circ}$ Curso sobre tecnologia de sementes de hortaliças, Petrolina-PE, Brasília: Embrapa Hortaliças. (CD-ROM).

NASCIMENTO, WM; BOITEUX, LS; GIORDANO, LB; GAGLIARDI, B; FREITAS, R. 2007. Seed germination response of inbred lines and their reciprocal "San
Marzano" tomato hybrids cultivated under different temperatures. In: $28^{\circ}$ ISTA Congress, $15^{\circ}$ Congresso Brasileiro de Sementes. Foz do Iguaçu. Seed Symposium Abstracts p. 84.

ORSI, CH; TANKSLEY, SD. 2009. Natural variation in an $\mathrm{ABC}$ transporter gene associated with seed size evolution in tomato species. PLoS Genetics 5(1):e1000347. doi:10.1371/ journal.pgen.1000347.

PONTES, A. 2006. Mercado de sementes de hortaliças. In: Palestras do $6^{\circ}$ Curso sobre tecnologia de produção de sementes de hortaliças, Goiânia. Brasília: Embrapa Hortaliças. (CD- ROM).

POTACZEK, H; KOZIK, EU. 2000. Low temperature seed germination of several tomato genotypes. Acta Physiologiae Plantarum 22: 293-295.

RAMALHO, MAP; SANTOS, JB; PINTO, CB. 2001. Genética na agropecuária. $2^{\mathrm{a}}$ ed. Lavras: Editora UFLA. 472p.

SEMEL, Y; NISSENBAUM, J; MENDA, N; ZINDER, M; KRIEGER, U; ISSMAN, N; PLEBAN, T; LIPPMAN, Z; GUR, A; ZAMIR, D. 2006. Overdominant quantitative trait loci for yield and fitness in tomato. Proceedings of the National Academy of Sciences 103: 12981-12986.

SILVERTOWN, JW. 1981. Seed size, life span, and germination date as coadapted features of plant life history. American Naturalist 118: 860-864.

VILELA, NJ; MELO, PCT; BOITEUX, LS; CLEMENTE, FMVT. 2012. Perfil socioeconômico da cadeia agroindustrial no Brasil. In: CLEMENTE, FMVT; BOITEUX, LS (org). Produção de tomate para processamento industrial. $1^{\mathrm{a}}$ ed., Brasília: Embrapa, 2012. p. 17-27. 